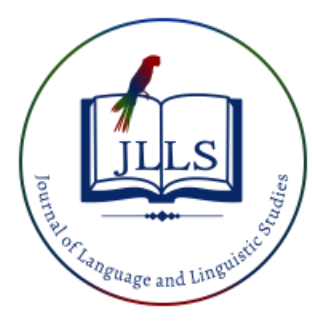

Available online at www.jlls.org

JOURNAL OF LANGUAGE AND LINGUISTIC STUDIES

ISSN: $1305-578 \mathrm{X}$

Journal of Language and Linguistic Studies, 16(4), 1987-2002; 2020

\title{
Challenges of translating neologisms comparative study: Human and machine translation
}

\author{
Awadh Nasser Munassar Awadh a 1 iD, Khan Ansarullah Shafiull ${ }^{\text {b }}$ iD \\ a Dr. Babasaheb Ambedkar Marathwada University, Aurangabad, India \\ b Mrs. K.S.K. Arts, Science, \& Commerce College Beed, India
}

\begin{abstract}
APA Citation:
Awadh, A. N., \& Khan A. S. (2020). Challenges of Translating Neologisms: Comparative Study, Human and Machine Translation. Journal of Language and Linguistic Studies, 16(4), 1987-2002.

Submission Date:29/05/2020

Acceptance Date:14/07/2020
\end{abstract}

\begin{abstract}
This study aims at investigating the challenges that Yemeni translation students encounter when translating neologisms from English into Arabic. It also aims at comparing students' translation with outcomes of machine translation (MT). The authors follow the descriptive and comparative methods in conducting this study. To achieve the objective of the study, a test consisted of 24 items was designed to uncover such difficulties and was given to 55 translation students. The same test was applied on three translation applications for comparing the performance of students with MT. The findings show that translating neologisms accurately is hard for most of the Yemeni translation students and also for machine translation as well. It is difficult for them to understand English neologisms or to find the Arabic equivalents for English neologisms. The finding also indicates that only a few translation students can achieve accurate translation. Meanwhile, Translation applications produced poor translation and could not able to achieve accurate translation for most types of neologisms. As a result of the comparison, students produced acceptable translation better than MT. The difficulties are lexical related to the twelve types of neologisms based on Newmark classification (1988).
\end{abstract}

c) 2020 JLLS and the Authors - Published by JLLS.

Keywords: Translation; neologisms; machine translation; Google translate; Systran; Al-Wafi.

\section{Introduction}

The world witnesses, at the present time, a great revolution in technology that touches almost all the facets of human life. The technical and scientific revolution, as one of the most important phenomena of the present, makes essential changes to the linguistic model of the world. Linguistically speaking, this results in the creation of new words or new lexical meanings for existing words. Many experts call these new terms "neologism". Newmark (1988) describes neologisms as "a newly coined lexical units or existing lexical units that acquire new sense" (p. 140).

Translating neologisms from one language into another has become very necessary to keep up with global development. As a matter of fact, translation has a major role in exchanging information and knowledge between nations. Thus, it helps in spreading scientific achievements all over the world.

\footnotetext{
${ }^{1}$ Corresponding author.

E-mail address: awadhnasser83@gmail.com
} 
However, translation is not an easy job, especially when it has to do with two languages that belong to two different language families and are different in culture, alphabet, and structure, as with English and Arabic.

Challenges of translating neologisms can be arisen from the complex nature of such terms, especially that are related to the technical and technology field. Therefore, this paper attempts to investigate the neologisms as one of the most common challenges for translation students and machine translation as well. For this reason, it aims to investigate the difficulties that face translation students and compare these difficulties with translating neologisms by machine translation. It also suggests some solutions to overcome such difficulties.

\subsection{Literature review}

\subsubsection{Importance of neologisms}

New words are produced, which enrich the language. Santhi (2010) states that each language acquires about 3000 new words every year, which are known as neologisms. Santhi (2010) also describes neologisms as the way that reminds us that language is not something set in stone, but an evolving body of work, subject to adjustment, deletions, additions, and change. As new things are invented, as slang becomes acceptable, and as new technologies emerge, new words must fill in the gaps in language. Similarly, Bakhtiyorovna (2013) claims that new science is impossible without neologisms, new words, or new interpretations of old words to describe and explain reality in new ways. To reject neologisms, that means, to reject scientific and technical developments. Furthermore, Khan (2013) describes neologisms as an important morphological process to produce new words in a language. It is used as one of the ways to generate new words in a language. Finally, neologisms, as a linguistic phenomenon, is a must to enrich any language, as well as to go with technical and technological developments.

\subsubsection{Types of neologisms}

Newmark (1988) proposes twelve types of neologisms; old words, old collocations with new meanings, new coinages, derived words, abbreviations, collocations, eponyms, phrasal words, transferred words, acronyms, pseudo neologisms, and internationalism. Examples for neologisms are many, such as a mouse, noob, malware, avatar, notebook, MOOC, pascal, lurkers, work out, zen mail, assp, spam, etc.

\subsubsection{Scope of neologisms}

Neologisms are found in various domains. According to Yasin, Mustfa, \& Faysal (2010) the domains of neologisms are divided into nine as the following; scientific, technological, political, pop-culture, imported, trademarks, nonce words, and inverted words. However, these domains are not absolutes and there may be other domains obtainable from the linguistic world.

\subsubsection{Previous Studies related to translating neologism}

Newmark (1988) describes translating neologisms as non-literary translation, but they seem to be one of the biggest problems for translation students because such types of words are not readily found in ordinary and even in some specialized dictionaries. Several studies describe translating neologisms as a difficult task for translators. Newmark (1995) describes translating neologisms as the most critical problem for translators. Moreover, Molavi (2012) also describes translating neologisms as a difficult task because they may not readily be found in Ordinary and even in specialized dictionaries. Also, Hammed (2009) considers neologisms as a serious obstacle in translating. Some previous studies, such as Molavi (2012), Hammed (2009), and Al-Kaabi (2005) confirm that translation translators have been suffering from the difficulties they face when translating neologisms. In the same regard, Hammed (2009) considers neologisms as a linguistic phenomenon which is very helpful for any language due to 
their elements that lend a language dynamism, indicative of language change, help to change the productive power of morphology of a language but they have serious obstacles in translation. Bakhtiyorovna (2013) indicates that the problem of translating neologisms is connected to the modern rapid period of development of science and technology. Whereas Hanaqtah (2016) describes the difficulties faced by translators in translating neologisms as problems related to cultural and technical terminology. He adds that the main problem is students' inability to find the right equivalents in Arabic for these neologisms. Another problem is the lack of information about the meaning of these neologisms in dictionaries. In addition to that, there are problems related to the idiomatic structure of some neologisms because these terms have particular meanings different from the meaning of each word on its own. For all the mentioned problems, some translation students in most cases fail to convey the same impact as the SL which leads to inaccurate and inadequate translation.

\subsection{The Statement of the Problem}

Based on the urgent need to keep up with such developments, translating neologisms became very necessary. However, translating such terms may constitute one of the most difficulties, facing translation students and machine translation as well. Thus, the paper attempts to shed light on the difficulties that translation students may encounter when translating neologisms with a comparison with machine translation for the same neologisms.

\subsection{The Objectives of the Study}

This study aims at investigating the challenges that Yemeni translation students face when translating neologisms from English into Arabic and comparing human translation to machine translation regarding translating the same neologisms.

\subsection{The Questions of the Study}

This study attempts to find answers to the following questions

1. What are the challenges that Yemeni translation students face when translating neologisms from English into Arabic.?

2. What are the differences between human translation and machine translation regarding translating the same neologisms?

\subsection{The hypotheses of the study}

The following hypotheses have been formulated as such:

1. Yemeni translation students and machine translation face challenges in translating neologisms from English into Arabic.

2. Translating neologisms by humans is better than machines.

\subsection{The Significance of the study}

The importance of this study stems from the fact that it deals with a topic of great importance today (i.e. Neologisms). The study is significant due to the importance of developments in science and technology. To the best of the researchers' knowledge, there are a few studies such as Alawneh (2007), Hammed (2009), and Molavi (2012) among others, that have dealt with the challenges pertinent to translating neologisms in various fields. Therefore, the present study is significant since it will fill a gap in an important area in the literature related to translating neologisms and it may motivate other 
researchers to conduct more studies on the same line. Besides, it will be useful also for translation students, machine developers, teachers, curriculum designers, and other related entities concerned with translation.

\subsection{Limitations of the Study}

The study has limitations related to time, place, participants, and subject matter. It was conducted during the 2nd semester of the academic year 2019/2020, Sana'a University, Yemen. The population was limited to level four translation students. On the other hand, three translation applications ((Google, Systran, and Al-Wafi) were selected as a sample for machine translation. The challenges of translating neologisms only from English into Arabic were discussed in the present study. Texts are very wide. However, the study was limited to neologisms related to the computer, the Internet, and electronic texts.

\section{Method}

The authors followed an analytical descriptive and comparative approach in collecting data.

\subsection{Sample / Participants}

The study population is level four translation students at the Faculty of Languages-Sana'a University during the 2nd semester of the academic year 2019/2020. They were chosen since they had studied more than 20 courses in translation for four years and, hence, were supposed to have sufficient background with a good mastery of translation from English into Arabic and were about to graduate. The total number of the population is seventy-three students ( 27 males and 46 females).

Sana'a University was selected because it is the first established university in the Republic of Yemen and is the only one that has a separate department of translation among public and private universities in Yemen. Besides, Sana' a University is considered as the biggest population university for both males and females. Moreover, it has a good number of specialized professors in translation and linguistics field, which enable the researchers to conduct their studies in the appropriate community. Students at Sana'a University come from various places in Yemen. The whole population (73 students) was taken as a sample of the study. However, 12 students (6 males and 6 females) were excluded since they participated in the pilot study and six were absent. Thus, the total number of the sample was 55 students (19 males and 36 females). On the other hand, three translation applications ((Google, Systran, and AlWafi) were selected as a sample for machine translation. They were chosen since they have common use among translators and others. hence, they were supposed to have sufficient capacity for translation.

\subsection{Instruments and procedures}

The test was designed to explore the challenges that translation students and machine translation face when translating neologisms from English into Arabic. First, the researchers prepared the first draft of the test by selecting (48) neologisms that were selected from different sources related to the computer, Internet and electronics, to satisfy the twelve types of neologisms based on Newmark classification (1995). The authors refer to Word Spy (2018) (a site for the latest words), Information Technology Magazine (2008), Yahya (2007) (Mini Technopedia), Khatib (1999) (A new Dictionary of Scientific and Technical Terms), Al-Kilani (2004) (Dictionary of Computer and Internet Terminology) related to translating neologisms and technical texts as primary resources.

To examine the validity of the test and to ensure that the selected neologisms were appropriate for translation students, 48 neologisms in 48 statements were submitted to a panel of six university teachers 
who have experience in translation and linguistics. The panel was requested to indicate whether each statement was clear, correct, and relevant and whether each neologism was suitable or not for the participants' level. They were also requested to add, delete, or modify any item and write any comment. Their suggestions and recommendations were taken into consideration in the final version of the test. Some neologisms were deleted: e.g. 7, 16, 24, 32,35,40, and 44, which were not related to the technical field. Based on the experts' responses, the researchers included in the final version of the test only those items that achieved $87 \%$ or above agreement among experts.

After the validation of the test, the researchers conducted a pilot study on 12 participants ( 6 males and 6 females). Some instructions were given to the participants before piloting the test and were given a chance to ask questions or make comments. Moreover, the Alpha Cronbach value of the test was $80 \%$, which indicates high reliability and internal consistency. The items 1, 6, 10, 12, 14, 16, 21, 24, 26, 30, 33, and 35 were omitted since their Alpha Cronbach value was lower than the accepted value. Finally, 24 statements were included in the final version of the test (see appendix).

\subsection{Data Analysis}

First, the participants' responses were collected and then given to two translators who have experience more than five years in translation. The translators were asked to rate the participants' translation of neologism as: untranslated, unacceptable, acceptable, or accurate. However, the main role of the translators was limited, to identify the acceptable and unacceptable translation only. Moreover, the researchers based their analysis on validators' translation which is considered as a measurement for the quality of translation. for statistical purposes, the scoring system was based on approval criterion, as follows: zero-point score was given to any untranslated item or any unacceptable translation, one-point score was given to each acceptable translation, and two-point score to each accurate and comprehensible translation. The answer was considered accurate if the neologism was rendered correctly without any mistake. Whereas the answer was considered acceptable if the neologism was rendered correctly, but sometimes with some linguistic errors that did not change the meaning. Finally, the answer was considered wrong and unacceptable if the answer failed to render the meaning of neologism or committed some fatal linguistic errors that changed the meaning. Finally, SPSS software was used to analyze the data. Percentage values were used to identify the difficulties of translating for each category of neologisms in regarding students or machine.

\section{Results and Discussion}

This section presents the findings and the answers to the question of this study. The researchers used a test to investigate the difficulties that translation students encounter when translating neologisms from English into Arabic with a comparison of machine translation for the same neologisms. It included 24 statements and 24 neologisms selected from various scientific sources and divided based on Newmark's (1988) classification. Percentage values and frequencies were used to highlight the difficulties that face students and machine translation while translating each category of neologisms.

\subsection{Students performance in translating neologisms}

There are 110 responses for each type of neologisms, which fall in either of the four criteria (untranslated, unacceptable, acceptable, and accurate translation). Table (1) shows details about the performance of the participants on the translation test in relation to each type of neologism under each of these criteria. For the sake of evaluating the participants' performance, the researchers set specific percentage criteria for levels of translation performance. Values under $50 \%$ are considered unacceptable translation, whereas values from 50 up to $75 \%$ are considered acceptable translation, and values 
between $75 \%$ and $100 \%$ are accurate translation. Table (1) also shows the participants' performance on the translation test and whether or not they encounter difficulties in translating neologisms. To give a clear picture of the difficulties facing translation students when translating neologisms from English into Arabic, the researchers arrange the types of neologisms according to their level of difficulty from the most difficult to the least on the bases of their results in the following table:

Table 1. Participants' Performance on the Translation Test

\begin{tabular}{|c|c|c|c|c|c|c|c|c|c|c|c|}
\hline \multirow{2}{*}{$\begin{array}{l}\text { Types } \\
\text { Neologisms }\end{array}$} & \multicolumn{2}{|c|}{ Untranslated } & \multicolumn{2}{|c|}{\begin{tabular}{|l|}
$\begin{array}{l}\text { Unacceptable } \\
\text { Translation }\end{array}$ \\
\end{tabular}} & \multicolumn{2}{|c|}{\begin{tabular}{|l|} 
Acceptable \\
Translation
\end{tabular}} & \multicolumn{2}{|c|}{\begin{tabular}{|l|}
$\begin{array}{l}\text { Accurate } \\
\text { Translation }\end{array}$ \\
\end{tabular}} & \multirow{2}{*}{$\begin{array}{l}\text { The } \\
\text { difficulty } \\
\%\end{array}$} & \multirow[t]{2}{*}{$\begin{array}{l}\text { Rank of } \\
\text { difficulty }\end{array}$} & \multirow[t]{2}{*}{ Result } \\
\hline & $F$ & $\%$ & $\mathrm{~F}$ & $\%$ & $\mathrm{~F}$ & $\%$ & $\mathrm{~F}$ & $\%$ & & & \\
\hline $\begin{array}{l}\text { New } \\
\text { collocations }\end{array}$ & 14 & 12.73 & 83 & 75.45 & 10 & 9.09 & 3 & 2.73 & 88.18 & 1 & Unacceptable \\
\hline Derived words & 15 & 13.64 & 66 & 60.00 & 12 & 10.91 & 17 & 15.45 & 73.64 & 2 & Unacceptable \\
\hline Acronyms & 17 & 15.45 & 56 & 50.91 & 23 & 20.91 & 14 & 12.73 & 66.36 & 3 & Unacceptable \\
\hline $\begin{array}{l}\text { Transferred } \\
\text { words }\end{array}$ & 3 & 2.73 & 70 & 63.63 & 3 & 2.73 & 34 & 30.91 & 66.36 & 3 & Unacceptable \\
\hline Phrasal words & 6 & 5.45 & 62 & 56.36 & 16 & 14.55 & 26 & 23.64 & 61.81 & 4 & Unacceptable \\
\hline $\begin{array}{l}\text { Old collocations } \\
\text { with new } \\
\text { meanings } \\
\end{array}$ & 1 & 0.91 & 64 & 58.18 & 25 & 22.73 & 20 & 18.18 & 59.09 & 5 & Unacceptable \\
\hline New Coinage & 12 & 10.91 & 48 & 43.64 & 29 & 26.36 & 21 & 19.09 & 54.55 & 6 & Unacceptable \\
\hline Eponyms & 12 & 10.91 & 47 & 42.73 & 31 & 28.18 & 20 & 18.18 & 53.64 & 7 & Acceptable \\
\hline $\begin{array}{l}\text { Old words with } \\
\text { new meanings }\end{array}$ & 1 & 0.91 & 52 & 47.27 & 16 & 14.55 & 41 & 37.27 & 48.18 & 8 & Acceptable \\
\hline $\begin{array}{l}\text { Pseudo } \\
\text { neologisms }\end{array}$ & 13 & 11.82 & 35 & 31.82 & 32 & 29.09 & 30 & 27.27 & 43.64 & 9 & Acceptable \\
\hline Abbreviations & 3 & 2.73 & 39 & 35.45 & 53 & 48.18 & 15 & 13.64 & 38.18 & 10 & Acceptable \\
\hline Internationalism & 11 & 10.00 & 17 & 15.45 & 28 & 25.46 & 54 & 49.09 & 25.45 & 11 & Acceptable \\
\hline Total & 108 & 8.18 & 639 & 48.41 & 278 & 21.06 & 295 & 22.35 & 56.59 & & Unacceptable \\
\hline
\end{tabular}

F: Frequency is the number of responses for each type of neologism out of 110.

Table (1) shows the frequencies and percentages of the participants' performance on the translation test. It indicates that (43.41\%) of the participants' translation was either acceptable $(21.06 \%)$ or accurate translation $(22.35 \%)$. However, (56.59\%) of their translation was either unacceptable or left untranslated. This data reflects the level of difficulty that translation students face in translating neologisms from English into Arabic. Thus, translating neologisms seems to be a real difficulty for most of the participants. The data projected in Table (1) also show that the participants achieved acceptable translation with certain types of neologisms, such as those related to the last four types as shown in the table above. However, they failed in translating the other types of neologisms at various degrees. The most difficult one seems to be translating new collocations. Therefore, $88.18 \%$ of the participants' translation was unacceptable translation. Moreover, the overall result of translating neologisms was unacceptable translation $56.59 \%$, whereas $43.41 \%$ was acceptable translation. Furthermore, the percentage given in the table also shows that the participants still suffer from some problems in translating certain neologisms as mentioned above. 


\subsection{Machine performance in translating neologisms}

The following table gives a clear picture of difficulties of translating neologism by using machine translation when translating such terms from English into Arabic:

Table 2. Machine' performance on the translation test

\begin{tabular}{|c|c|c|c|c|c|c|c|c|c|c|c|}
\hline \multirow{2}{*}{$\begin{array}{l}\text { Types of } \\
\text { Neologisms }\end{array}$} & \multicolumn{2}{|c|}{ Untranslated } & \multicolumn{2}{|c|}{\begin{tabular}{|l|} 
Unacceptable \\
Translation \\
\end{tabular}} & \multicolumn{2}{|c|}{\begin{tabular}{|l|} 
Acceptable \\
Translation \\
\end{tabular}} & \multicolumn{2}{|c|}{\begin{tabular}{|l|} 
Accurate \\
Translation
\end{tabular}} & \multirow[t]{2}{*}{$\begin{array}{l}\text { The difficulty } \\
\%\end{array}$} & \multirow[t]{2}{*}{$\begin{array}{ll}\text { Rank } & \text { of } \\
\text { difficulty } & \end{array}$} & \multirow[t]{2}{*}{ Result } \\
\hline & $\mathrm{F}$ & $\%$ & $\mathrm{~F}$ & $\%$ & F & $\%$ & $\mathrm{~F}$ & $\%$ & & & \\
\hline $\begin{array}{l}\text { New } \\
\text { collocations }\end{array}$ & & & 3 & $\mathrm{~S}, \mathrm{G}, \mathrm{W}$ & & & & & $100 \%$ & 1 & Unacceptable \\
\hline Derived words & 1 & \begin{tabular}{|c|}
$\mathrm{W}$ \\
$33.33 \%$ \\
\end{tabular} & 2 & $\begin{array}{c}\mathrm{S}, \mathrm{G} \\
66.67 \%\end{array}$ & & & & & $100 \%$ & 1 & Unacceptable \\
\hline Acronyms & 2 & \begin{tabular}{|c|}
$\mathrm{G}, \mathrm{W}$ \\
$66.67 \%$ \\
\end{tabular} & 1 & $\begin{array}{c}\mathrm{S} \\
33.33 \% \\
\end{array}$ & & & & & $100 \%$ & 1 & Unacceptable \\
\hline Phrasal words & & & 3 & $\mathrm{G}, \mathrm{S}, \mathrm{W}$ & & & & & $100 \%$ & 1 & Unacceptable \\
\hline \begin{tabular}{|lr|}
\multicolumn{2}{|c|}{ Old collocations } \\
with & new \\
meanings &
\end{tabular} & & & 3 & $\mathrm{~S}, \mathrm{G}, \mathrm{W}$ & & & & & $100 \%$ & 1 & Unacceptable \\
\hline New Coinage & 1 & \begin{tabular}{|c|}
$\mathrm{W}$ \\
$33.33 \%$ \\
\end{tabular} & 2 & $\begin{array}{c}\mathrm{S}, \mathrm{G} \\
66.67 \%\end{array}$ & & & & & $100 \%$ & 1 & Unacceptable \\
\hline $\begin{array}{l}\text { Old words with } \\
\text { new meanings }\end{array}$ & & & 2 & $\begin{array}{c}\mathrm{W}, \mathrm{S} \\
66.67 \%\end{array}$ & & & 1 & $\begin{array}{c}\mathrm{G} \\
33.33 \%\end{array}$ & $66.67 \%$ & 2 & Unacceptable \\
\hline Abbreviations & 2 & \begin{tabular}{|c|}
$\mathrm{G}, \mathrm{W}$ \\
$66.67 \%$ \\
\end{tabular} & 1 & $\begin{array}{c}\mathrm{S} \\
33.33 \%\end{array}$ & & & & & $66.67 \%$ & 2 & Unacceptable \\
\hline $\begin{array}{l}\text { Transferred } \\
\text { words }\end{array}$ & 1 & \begin{tabular}{|c|}
$\mathrm{W}$ \\
$33.33 \%$ \\
\end{tabular} & 1 & $\begin{array}{c}\mathrm{S} \\
33.33 \% \\
\end{array}$ & 1 & $\begin{array}{c}\mathrm{G} \\
33.33 \% \\
\end{array}$ & & & $66.67 \%$ & 2 & Unacceptable \\
\hline Eponyms & & & & & 2 & $\begin{array}{c}\mathrm{G}, \mathrm{W} \\
66.67 \%\end{array}$ & 1 & $\begin{array}{c}\mathrm{S} \\
33.33 \%\end{array}$ & 0 & 3 & Acceptable \\
\hline $\begin{array}{ll}\text { Pseudo } \\
\text { neologisms }\end{array}$ & & & & & & & 3 & $\begin{array}{c}\text { G, S, W } \\
100 \%\end{array}$ & 0 & - & Acceptable \\
\hline Internationalism & & & & & & & 3 & $\begin{array}{c}\text { G, S, W } \\
100 \%\end{array}$ & 0 & - & Acceptable \\
\hline Total & 7 & 19.45 & 18 & $50 \%$ & 3 & 8.33 & 8 & 22.22 & $69.45 \%$ & & Unacceptable \\
\hline
\end{tabular}

F: Frequency is the number of responses for each type of neologism out of 110.

The data projected in the table (2) indicate that the machine translation (Google, Sysran, and AlWafi) achieved acceptable translation with a few types of neologisms, as shown in the table above. However, these translation applications failed in translating the most types of neologisms at various degrees. The most difficult one seems to be translating new collocations for both humans and translators as shown in Tables (1and 2). Furthermore, the percentage given in the tables also shows that translating neologisms is a hard task for both machines and participants but the participants are still better than the machine. All the types of neologisms will be discussed each one separately, starting from the highest level of difficulty to the lowest with the comparison with human and machine translations, based on Newmark classifications (1995) as follows:

\subsection{New Collocations}

New collocation is expressions of two or more words (i.e. neologism) that occur. The tables (1) and (2) mentioned above, show that new collocations obtained the highest percentage of difficulty among the other types for human and machine translation as well. The collocation "power boost" is a clear example of this type. It was translated in various ways. Only a few of the participants achieved an accurate translation and acceptable whereas the remaining were unacceptable, i.e. (مقادة), الإنشارة), while the majority produced wrong translations, such as (مزود الطاقة, مدعم الطاقة, تعزيز القوة, زيادة كبيرة) on other hand, the translation of all three machine applications was unacceptable as (زيادة الطاقه أو تعزيز الطاقة). indicates that the participants and machines face a high difficulty in translating neologisms related to new collocations. This result is consistent with Ghazala's (2008) conclusion which indicates that translating collocations is problematic since it is strongly connected to technology developments and 
since the dictionaries do not often help translators in finding the intended meaning, especially when these collocations come as neologisms. This type of neologism is new and is not available in any dictionary. Therefore, most participants used literal translation, and consequently, the majority of translations were unacceptable, and also it is not available in the database of machine translation.

\subsection{Derived Words}

This category of neologism refers to the forming of new words based on existing words. Table (1) illustrates that a few of the participants' translations were either accurate or acceptable. Yet, a high percentage of their translations were either unacceptable or untranslated. As shown in Table (1), translating this type of neologisms got the second rank in terms of difficulty among the other types. This indicates that most participants faced difficulty in translating derived words. Similarly, the machine faced difficulty in translating such words and got also the first rank of difficulty.

An example of this type of neologisms is the term "screenagers". Few participants translated it as which were either accurate or acceptable translations. On the other hand, the majority of the participants translated this term as (الثشاشه, المشيشين) which were unacceptable translations. Regarding machine translation was wrong by all three applications (السيناريو , الغرباء). The result shows that the majority of the participants and machine Applications did not work well in translating derived words. This could be due to the affixes associated with such neologisms which lead to various meanings. However, this finding is inconsistent with those found in Lina (2016) and Argeg (2015) who confirm that translating derived words constitute a difficulty for translators. That might be because derived words often carry different meanings from the original ones. Thus, translating this type represents a difficulty for most translators as well as machines.

\subsection{Acronyms}

This category of neologism is a kind of abbreviations used as a word which formed from the initial letters of a group of words. Translating acronyms obtained the third-highest level of difficulty as shown in Tables (1 and 2). The acronym MOOC (massive open online courses) is an example of this type of neologism. It was translated in various ways. few of the participants gave either an acceptable or accurate translation, such as (المساقات أو دروس مفتوحة عبر النت). Whereas most of them gave the wrong translation such as (منحه موك,كتب.), machine translation failed too in translating it by leaving this neologism untranslated or translated as transcription MOOC.

According to the researchers' knowledge, there are many difficulties faced by translators when translating acronyms. The first one is related to the difficult structure of the acronym which is difficult to understand without a background. Second, the translators and machine may not get benefit from the context effectively. Third, the participants might be unable to use appropriate strategies instead of transcription. Thus, translating this type of neologisms is considered as one of the critical difficulties for translation translators for human and machine translation, as shown in Table (1 and 2) so the students should be careful in translating such a kind of terms to avoid falling in a bad consequence.

Najeeb (2005) has found a similar result regarding translating acronyms which constitutes a big difficulty. Thus, translators should use good dictionaries to achieve an accurate translation, unless they only may guess the meaning wrongly. Also, they should know the common use of acronyms that are widely used. Similarly, Ghazala (2008) agrees that acronyms include some problems for the students of translation as well as trainee translators. 


\subsection{Transferred Words}

Transferred words are loan words (i.e. neologism) taken from other languages. Table (1 and 2) indicates that transferred words obtained the third rank of unacceptable translation among the other types and difficulties related to student translation whereas it came in the fourth rank related to machine translation but almost the same percentage of difficulty they faced. This shows that the participants face some difficulty in translating this type of neologisms and machine as well.

Avatar which is transferred from Sanskrit language is an example of this type. It was translated in various ways. Some of the participants achieved either acceptable or accurate translation, such as (شورة)

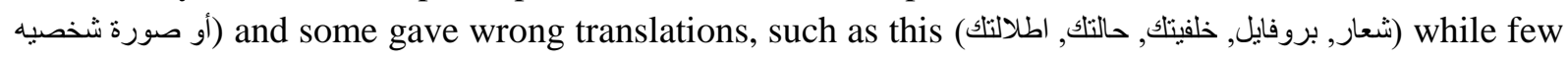
were left untranslated. This neologism is difficult for some participants because may they were unable to find and understand suitable equivalences. In comparison to machine translation, this term was translated correctly by Google while unacceptable by Sysran and left without translation by ALWafi as shown (Table 2).

Newmark has a similar result related to the difficulty of translating transferred words because their meanings are, at least, dependent on context. Besides, these words constitute difficulty because they are borrowed from other languages. Moreover, these words may be new to most speakers of the receptor language. That is because they include such names of people, geographical areas, things, and places. Thus, translating this type of neologisms was a problem, especially for the machine or the participants who could not take the context in their account.

\subsection{Phrasal Words}

This category of neologism is including phrasal verbs and nouns. Translating phrasal words is in the fourth rank of difficulties among other types related to translation students as shown in Table (1) while it comes in the first rank also regarding machine translation. Therefore, the data reveals that is a big number for participants and machine to translate such type of neologisms. For instance, the phrasal word up-market is an example of this type. Only a few of the participants produced accurate translations, such as (غالي وعالي الجودة) and others gave a wrong translation such as this (منوفر بالسوق, مرغوب في السوق)

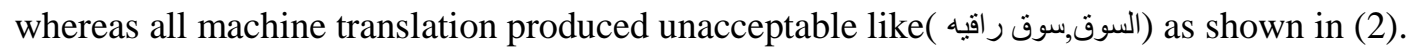

The result indicates that most participants encounter difficulty in translating the neologisms related to phrasal words. Ghazala (2008) describes translating phrasal words into Arabic is a big problem for many students as well as translators. Finding and understanding Arabic equivalents of phrasal words can be done through using the context which plays a major role in translating such a kind of expression.

\subsection{Old collocations with New Meanings}

This type of neologisms is called old collocation with new meaning. Translating this type of neologisms is in the fifth rank in difficulty among other types regarding participants whereas in the first rank to the machine. The collocation notebook is an example of this type as shown in the above tables. It was translated in various ways. few of the participants achieved accurate or acceptable translations

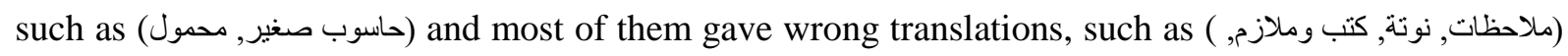

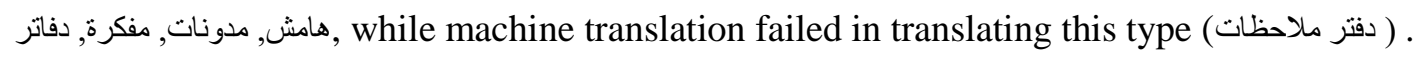

The result shows that machine translation and most of the participants encountered difficulty in translating neologisms of old collocations which have new meanings in addition to old ones. Therefore, a good number of the participants faced ambiguity in translating such a type of neologisms because it has a new in addition to its old meaning. However, some of the participants were not aware of the context to disambiguate this collocation. This result is similar to Newmark's result(1988) which describes translating collocations as a translator's trap because these collocations are usually normal descriptive 
terms which suddenly become technical terms, and therefore their meanings sometimes hide innocently behind a more general or figurative meaning

\subsection{New Coinages}

New coinages are new words that are coined without using other words formation processes. This type of neologisms is called new coinage. As shown the neologism 'noobs' is a clear example of this type. It was translated in various ways. some of the participants' achieved correct translations, such as (مبندئين) while others produced wrong ones, such as (نوبس).On the other hand, all three machines failed in translating this neologism and left it as (noob) without translation as mentioned in Table (2).

The result indicates that many of the participants encounter difficulty in translating new coinages because such words are new. Moreover, most of the previous studies which addressed neologisms dealt with new coinages as neologisms, not as one of the twelve types. The result also shows the participants' weakness in understanding Arabic equivalence which may play a negative role in translating such words. Similarly, Ghazala (2008) considered the use of unsuitable strategy as a common mistake that is committed by the students when they take the literal translation as to be an applicable way to translate everything in language.

\subsection{Eponyms}

Eponyms are words derived from proper names. The eponym voltmeter is an example of this type, as shown in above tables, half of the participants achieved accurate or acceptable translations such as and the remaining produced wrong translations, whereas few were left blank. The result also shows that all used machine translation produced acceptable and accurate translation for such neologisms. However, some of the participants still face difficulty in translating this type of neologism. This type of neologism is in the seventh rank of having unacceptable translations as shown in Table 1 while no difficulty for translating it by machine translation. According to Newmark (1988) eponyms are derived from famous and known persons. It is difficult for some of the participants to translate this type properly but it is easy to be translated by machine as known and famous words as shown on Table 2 . In respect of reason for the difficulty is probably the lack of knowledge in this field. When an eponym refers directly to a person, it is translated without difficulty, but when it refers to an object, the translator in this case faces problems in translating it.

\subsection{Old Words with New Meaning}

This type of neologisms called old words that additionally are used with new meanings. As shown in Table $1,51.82 \%$ of the participants' translations were either accurate translations $(37.27 \%)$ or acceptable translations (14.55\%). Yet, $47.27 \%$ of their translations were unacceptable and $0.91 \%$ were left untranslated. For instance, the word "burn" is an example of this type, as shown in Appendix 8. It was translated in various ways. Only $29.01 \%$ of the participants have given accurate translations, such يتلف, يحذف, يسجل, املاء, وضع, ,يحرق, يشغل يستمع (انسخع whereas 70.09\% have given wrong translations, such as (استعاره).

Old words with new meanings seem to be one of the least difficult types of neologisms. Moreover, the overall result of translating this type was an acceptable translation. However, translating this type of neologisms is still so difficult for machine translation because it may face ambiguity in translating such words. The machine may know only the common meaning of the polysomic word and they are usually used to be translated into Arabic, regardless of any new or other meanings. Thus, the machine might commit serious mistakes when translating this type of neologism. In this situation, choosing an inappropriate equivalent in the TL can cause linguistic problems, particularly in the technical field. The 
context of these words is very necessary to help translation students in identifying the proper translation while machines cannot use such context as human. Thus, this type of neologism is a very important factor for distinguishing between machine and human translation.

Argeg (2015) has a similar result, that the translator may face the problem of a word that has more than one meaning which is completely different in the SL and the TL, such as (burn in the above example). According to Ghazala (2008), such a kind of difficulty is a lexical one since such words are polysemous and thus ambiguous. On the other hand, the students still face lexical difficulties in translating such words because they have a new meaning in addition to the old one. To consult a dictionary, there are some possible meanings of the neologism burn but some of the participants tend to use the literal translation for this type, such as(يحرق)in the above example. Many reasons may cause the difficulties of translating this type, based on the interpretation of the study; The first reason may be the participants' ignorance of technical and linguistic context. The second reason may be due to the participants' inability to use a suitable strategy instead of literal translation.

\subsection{Pseudo-neologisms}

Pseudo - neologisms are generic words that stand for specific words and also called abbreviations. As shown in Table (1), most of the participants' translations were either accurate translations or acceptable translations. Yet, few of their translations were Wrong. The word, CD-ROM is an example of Pseudo - neologism. Most of the participants achieved accurate and acceptable translation for this neologism, such as (القرص المضغوط) and few of them translated it wrongly, such as (سيدي). In comparison to machine translation, all the translation applications as mentioned in table (2) produced correct translation for Pseudo - neologisms that is why such words may be known.

\subsection{Abbreviations}

Abbreviation the shorted form of a word or phrase. Table (1 and 2) shows that translating this type is an unacceptable translation regarding machine translation while acceptable for human translation. Therefore, it obtained the sixth rank of difficulty among the twelve types. The abbreviation "Nomonophopia." is an example of this type as shown in the above table .The participants translated this abbreviation in various ways. Some of the participants gave accurate translations, such as (الولع أو (إن ) or acceptable such as (إدمان الهو اتف (التخوف من البقاء بلا هاتف)whereas just most of them gave wrong translations such as (الخوف, الفوبيا) and few of the participants did not translate it. Table 2 shows that all machines face difficulty in translating abbreviations because they may not have a database related to such neologisms. However, the researchers think that some of the participants may resort to translating such abbreviations by guessing the meaning wrongly.

The result indicates that abbreviations type is considered one of the difficult types of neologisms especially for those interested in using machine translation. However, translating this type of neologism constitute a difficulty for some of the participants, especially in translating uncommon abbreviations. Some of the participants used an inappropriate strategy which may not help in translating such type of neologisms. In the same regard, Najeeb (2005) describes translating abbreviations as a difficult task, so specialized dictionaries and references should be used to avoid falling in bad consequences in case of guessing the meaning. Moreover, the common use of abbreviations should be known to be translated properly.

\subsection{Internationalism}

Internationalism is loanwords that occur in several languages with the same or at least similar meanings. It is clear from the table (1) that majority of the participants' translations were either accurate 
or acceptable. Also, Table (2) shows the result of translating this type is in the correct translation option $100 \%$ by using machine translation. Thus, there is no difficulty in translating such type of neologisms for both students' translation and machine translation. For instance, the word, computerization is an example of this type. The majority of the participants and all machines translation achieved accurate or acceptable translations such as (حوسبة, أنظمة حاسوب, الحواسيب), whereas few participants produced wrong translations, such as (إحصاء, كمبيوترات, الكترونيات).

The result clarifies that translating internationalism is the easiest type among other types of neologisms. Thus, this result could be accounted for one reason. The participants' familiarity and machine translation as well, with such neologisms which are viewed as common terms around the world. Newmark (1995) considers international words as "loanwords" that exist in several languages with the same or, at least, similar meaning and etymology. The authors think that most of the international words are known and available in most world languages and dictionaries.

To sum up, the results have shown that, although the participants used all the available sources of translation, such as hard and soft copies of dictionaries except machine translation, they were unable to achieve an accurate translation for most selected neologisms. Most of them were unable to find a suitable equivalent in the target language. This result is consistent with Kuzmina and Yusupova (2016) who consider finding a lexical equivalent as a problem in translating technical terms. Moreover, Argeg (2015) mentions that all languages are different, and thus, it is hard to find appropriate equivalents for some words or concepts in the target language. The results also show that some of the participants do not know the various types of neologisms and how to deal with each one, as shown in the results of the test in Table 1 and more difficult for the machine as shown in Table 2. Therefore, neologisms have lexical difficulties related to the twelve types of neologisms. According to Ghazala (2008), each type of neologism at the same time has a lexical difficulty. Thus, Nakhallah (2010) considers neologisms and their types, such as abbreviations and acronyms as one of the main difficulties in the translation field. Some theorists and scholars talk about the problems of translating neologisms in particular, such as Newmark (1988) who describes translating neologisms as the translator's biggest problem. The main problem in translating neologisms is that the translators and machine translations lack finding suitable equivalent terms in the target language. Thus, translating neologisms constitutes one of the most challenges and difficulties facing translation human and machine translation, and the hypotheses are proved that translating neologisms is difficult for translation students as human and machine translations. Also, human translation for translating neologisms is better than machine translation.

\section{Conclusions}

The results have indicated that translating neologisms accurately can be hard for most translation students and more difficult by using a machine. The participants encountered difficulty in understanding the intended meaning or in finding an Arabic equivalent. Table (1) shows that only about $22.35 \%$ of the total number of the participants were able to achieve accurate translation and about $21.06 \%$ acceptable. Similarly, Table (2) shows that only about $22.22 \%$ of the machine translations were able to produce an accurate translation and about only $8.33 \%$ as acceptable. This result is consistent with Newmark (1988) who describes translating neologisms as the biggest problem for translators due to the absence of target equivalence. Others like Hammed (2009) consider translating neologisms as a serious obstacle in the translation field. Translating neologism is a real problem for humans and machines as well. The results of this study also indicate that the majority of the participants were unaware of using appropriate strategies in translating neologisms. Therefore, they used some unhelpful ones excessively, such as 
transference and literal strategy. Furthermore, using machine translation does not help in translating neologisms except Pseudo and internationalism types.

Challenges of translating neologisms could have arisen from the complex nature of such terms, especially that are related to the technical and technology field. Therefore, such words are not readily found in ordinary and even in some specialized dictionaries and it is difficult to translation applications to translate such terms accurately. Another main difficulty is related to the various types of neologisms. Thus, most translation students may not be familiar with translating neologisms and they also fail to find an accurate equivalent term for a specific word in the source language. Although students' translation for neologisms is better than machines, translating neologisms is still one of the most challenges for translation students and machine translation as well.

\subsection{Recommendations}

Based on the previous discussion, the researchers suggest the following:

1. Specialized glossaries and dictionaries should include neologisms.

2. Translation applications should be updated to include new terms in general and all types of neologisms in particular.

3. Translation students and translators as well should be provided with the research skills needed to access various resources on websites.

4. Translators should be aware of the various types of neologisms and the strategies that could be applied to translate each type properly.

5. Translators should take into account achieving a translational equivalent of any neologism, considering the contextual use.

6. Individual translation efforts in translating neologisms should be supplemented by institutional efforts as it is a job that exceeds the individual translator's ability and capability of machines.

\section{Ethics Committee Approval}

The author(s) confirm(s) that the study does not need ethics committee approval according to the research integrity rules in their country (Date of Confirmation: December 11, 2020).

\section{References}

Alawneh, T. M. (2007). Translation of Neologisms of Two Palestinian Intifadas the First (1987-1993) and the Second (2000-2006) (Unpublished master thesis), An-Najah National University, Banjar, S. Nablus, Palestine.

Al-Kaabi, R. C. S. (2012). Translating English Military Neologisms into Arabic. Mustansiriyah Journal of Arts, (59), 1-28.

Al-Kilani, T. (2004). Al-Kilani Dictionary of Computer and Internet Terminology. Beirut: Libraire du Liban Publishers.

Argeg, G. (2015). The problems of translating medical terms from English into Arabic (Unpublished doctoral dissertation), Durham University. 
Bakhtiyorovna, R. (2013). Semantic and Functional Characteristics of Neologisms in Modern English (Unpublished master thesis), The Uzbek State World Languages University, Tashkent, Uzbekistan.

Ghazala, H. (2008). Translation as Problems and Solutions: A Course book for University Students and Trainee Translators (Special ed.). Beirut, Labnan: Dar El-ilmLilmalayin.

Hammed, S. G. (2009). Coping with Neologisms in English /Arabic Translation (Unpublished master thesis), American University of Sharjah, Sharjah, UAE.

Hanaqtah, M. F. (2016). Translating English Neologisms in Military and Political Texts into Arabic: Issues and Strategies (Unpublished doctoral dissertation), University Sains Malaysia.

Khan, M. (2013). Neologisms in Urdu A Linguistic Investigation of Urdu Media. Language in India, 13(6). 818-826.

Khatib, A. (1999). A New Dictionary of Scientific \& Technical Terms:English-Arabic (2 ${ }^{\text {nd }}$ ed.). Beirut: Librairie du Liban Publishers.

Kuzmina, O. D., \&Yusupova, L. G. (2016). Translation of the English Neologisms into the Russian and German Languages. International Journal of Humanities and Cultural Studies (IJHCS), 1(1), 206211.

Lina, Z. (2016). Neologisms in News English. Sino-English Teaching, 13(4), 292-295.

Molavi, B. (2012). An Analysis of the Most Frequently Used Strategies for Translating Neologisms in Economic Texts: From English into Persian (Unpublished master thesis), Islamic Azad University, Tehran, Iran.

Najeeb, E. (2005). Translation from English to Arabic and Vice Versa (5 ed.). Cairo, Egypt: Ibn Sina Library for Publishing and Distribution.

Newmark, P. (1988). A textbook of translation (Vol. 66). New York: Prentice hall.

Nakhallah, A. (2010). Difficulties and problems facing English students at QOU in the translation process from English to Arabic and their solutions. Al-Quds Open University. Retrieved May 10, 2019, from http://ilts.ir/Content/ilts.ir/Page/142

Santhi, D. D. (2010). Translating Neologisms. Retrieved October 12, 2019, from Dessy's Creative Page: http://dessydys.blogspot.com

Word Spy. (2017). Retrieved March 15, 2019 from https://www.wordspy.com

Yahya, M. M. (2007). Mini Technopedia. Egypt: Alexandria Library for Publishing and Distribution.

Yasin, A., Mustfa, A., \& Faysal, T., (2010). Neologism as a Linguistic Phenomenon in Mass Media Textbooks with Reference to Translation. Journal of Historical \& Cultural Studies, 2(6), 243-264. 
Appendix

\section{Translation Test}

\section{Dear student,}

We are conducting my study on "Challenges of Translating Neologisms from English into Arabic,

Comparative Study: Human and Machine Translation". This test aims to identify the difficulties of translating neologisms faced by translation students. Your translation for each of the following statements containing neologisms will certainly help us to obtain the intended results and come up with reasonable recommendations. The neologisms have been taken from three types of texts related to the computer, internet, and electronics fields, including various types of neologisms based on Newmark's classification.

Your cooperation is highly appreciated.

\section{Part (A) - Demographic Background}

1. Name. (optional).

2. Gender: Male $\square$ Female

Part (B)-Test

You are kindly requested to translate each statement with special attention to the underlined neologisms.

Example: Before performing any task on your computer, back up all personal files. قبل أداء أبي مهمه على حاسوبك، انسخ نسخة احتياطية لكل ملفاتكا الثخصية

1. I've texted him but got no reply.

2. You can burn CDs of your favorite music.

3. He will start by giving a little background for all the noobs who didn't have basic information about computers.

4. Typically updated daily, blog often reflects the personality of the author.

5. Press ALT +LF, to open the word options.

6. These memory module types are rarely used in desktop computers and never in notebooks.

7. Bluetooth provides up to $720 \mathrm{Kbps}$ data transfer within a range of 10 meters and up to 100 meters with a power boost.

8. We sometimes check our email, but we find only zen mail.

9. Set security options to protect your computer from malware.

10. Some people are fond of their phones to become nomonophopia.

11. To sign in in Gmail, you need to write your username and password.

12. New Apple devices are up-market.

13. Most lurkers confuse their friends in social networks because of their limited contributions.

14. Families should pay attention to screenagers in order to avoid wasting their time.

15. To open any file, click on the icon.

16. Your avatar on WhatsApp is not clear.

17. Programmers can give instructions to the computer through Pascal.

18. A voltmeter is an instrument used to measure differences in electronic potential.

19. With the emergence of the internet, lots of MOOCs occur and they can help those who do not have time for school.

20. RAM is a type of data storage used in computers.

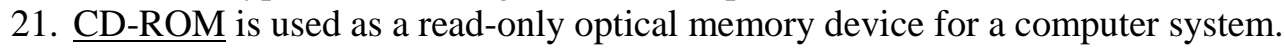

22. They googled his name and found out that he runs his own company.

23. Most of the professional and international institutes use computerization in all processes of their works.

24. With the emergence of new memories, disks become unused. 


\section{Neologismleri tercüme etmenin zorlukları}

\section{karş1laştırmalı çalışma: İnsan ve makine çevirisi}

\section{$\ddot{O} \mathbf{z}$}

$\mathrm{Bu}$ çalışma, Yemenli çeviri öğrencilerinin neologizmleri İngilizceden Arapçaya çevirirken karşılaştıkları zorlukları incelemeyi amaçlamaktadır. Ayrıca öğrencilerin çevirilerini makine çevirisinin (MT) sonuçlarıyla karşılaştırmayı amaçlamaktadır. Yazarlar, bu çalışmayı yürütürken tanımlayıcı ve karşılaştırmalı yöntemleri takip ederler. Çalışmanın amacına ulaşmak için, bu tür zorlukları ortaya çıkarmak için 24 maddeden oluşan bir test tasarlanmış ve 55 çeviri öğrencisine verilmiştir. MT ile öğrencilerin performanslarını karşılaştırmak için aynı test üç çeviri uygulamasına uygulanmıştır. Bulgular, neolojileri doğru bir şekilde çevirmenin Yemenli çeviri öğrencilerinin çoğu ve aynı zamanda makine çevirisi için zor olduğunu gösteriyor. İngiliz neolojizmlerini anlamaları veya İngilizce neologizmlerinin Arapça karşılıklarını bulmaları zordur. Bulgu aynı zamanda sadece birkaç çeviri öğrencisinin doğru çeviri yapabildiğini göstermektedir. Bu arada, Çeviri uygulamaları yetersiz çeviri üretti ve çoğu türden neologizm için doğru çeviri yapamadı. Karşllaştırmanın bir sonucu olarak, öğrenciler MT'den daha iyi kabul edilebilir çeviri ürettiler. Newmark sınıflandırmasına (1988) dayanan on iki tür neologizmle ilgili zorluklar sözcükseldir.

Anahtar Sözcükler: Çeviri; neolojizmler; makine çevirisi; Google Çeviri; Systran; Al-Wafi.

\section{AUTHOR BIODATA}

Awadh Nasser Munassar Awadh is a PhD scholar at Dr. Babasaheb Ambedkar Marathwada University, Department of English in translation field. He received his master's degree from Department of Englishtranslation major, University of science and technology, Yemen. His research areas include translation, translation technology, and technical translation.

Dr. Khan Ansarullah Shafiullah is an Assistant Professor and Head, Department of English, Mrs. K.S.K. Arts, Science, \& Commerce College Beed. He has been awarded PhD by Dr Babasaheb Ambedkar University Aurangabad on the topic Post modernism and Social Realism in the novels of Vikram Seth. 